\title{
Primary and Secondary Hyperparathyroidism in Patients with Primary Aldosteronism - Findings From the German Conn's Registry
}

\author{
Authors \\ Evelyn Asbach1, Margareta Bekeran'1, Anna König², Katharina Lang³, Gregor Hanslik ${ }^{4}$, Marcus Treit|5, \\ Roland Ladurner ${ }^{6}$, Martin Bidlingmaier ${ }^{1}$, Felix Beuschlein ${ }^{1}$, ${ }^{\text {, Marcus Quinkler }}{ }^{8}$, Martin Reincke ${ }^{1}$
}

\section{Affiliations}

1 Endocrinology, Medizinische Klinik und Poliklinik IV, Klinikum der Ludwig-Maximilians-Universität München, München, Germany

2 Klinik für Gastroenterologie, Hepatologie und Endokrinologie, Medizinische Hochschule Hannover

3 Medizinische Klinik I, Julius-Maximilians-Universität Würzburg, Germany

4 Klinische Endokrinologie, Charité Campus Mitte, Universitätsmedizin Berlin, Germany

5 Institut für Klinische Radiologie, Klinikum der LudwigMaximilians-Universität, München, Germany

6 Klinik für Viszeral-und Endokrine Chirurgie, Klinikum der Ludwig-Maximilians-Universität, München, Germany

7 Klinik für Endokrinologie, Diabetologie und Klinische Ernährung, Universitätsspital Zürich, Germany

8 Endokrinologie in Charlottenburg, Berlin, Germany

Key words

primary aldosteronism, aldosterone, vitamin D, primary hyperparathyroidism, secondary hyperparathyroidism

received 14.05 .2019

revised 27.09 .2019

accepted 14.10.2019

Bibliography

DOI https://doi.org/10.1055/a-1027-6472

Published online: 7.11.2019

Exp Clin Endocrinol Diabetes 2020; 128: 246-254

(c) J. A. Barth Verlag in Georg Thieme Verlag KG Stuttgart . New York

ISSN 0947-7349

\section{Correspondence}

Prof. Dr. M. Reincke

Medizinische Klinik und Poliklinik IV

Klinikum der Universität München

Ziemssenstraße 1

80336 München

Germany

Tel.: + 49-89-4400-52100, Fax: +49-89-4400-54428

martin.reincke@med.uni-muenchen.de

\begin{abstract}
Context Recent studies support a bidirectional interaction between aldosterone and parathyroid hormone (PTH), possibly increasing the individual cardiovascular risk. Primary aldosteronism (PA) and primary hyperparathyroidism can occur simultaneously.

Objective Our aim was to investigate the prevalence of hyperparathyroidism in PA.

Patients We performed a case finding of primary hyperparathyroidism in a retrospective series of 503 patients with PA (cohort 1). We analysed primary and secondary hyperparathyroidism in 141 prospective PA patients who underwent PTH, serum calcium and phosphate measurements at time of diagnosis of PA (cohort 2).

Results The prevalence for primary hyperparathyroidism was $1.2 \%$ in cohort 1 , and $2.1 \%$ in cohort 2 . Secondary hyperparathyroidism was found in $54.6 \%$ of the patients. Patients with secondary hyperparathyroidism had significantly higher aldosterone and lower potassium levels and took more antihypertensive medications compared to those with normal PTH levels. In multivariate analysis, aldosterone and 25-hydroxyvitamin D levels were significantly correlated with serum PTH levels. There was a nonsignificant trend to a higher cardiovascular morbidity in patients with secondary hyperparathyroidism. Patients with aldosterone producing adenoma had significantly higher PTH levels compared to patients with bilateral adrenal hyperplasia. After treatment, there was a significant decrease of PTH levels in both groups.

Conclusion Patients with PA frequently have primary or secondary hyperparathyroidism, which is alleviated by correction of PA by surgical or medical means. Patients affected by secondary hyperparathyroidism seem to have a more severe phenotype of PA and have a trend towards more cardiovascular co-morbidities.
\end{abstract}




\section{Introduction}

Primary aldosteronism (PA) represents the most frequent cause of endocrine hypertension [1]. The two main forms are aldosterone producing adenoma (APA) and idiopathic bilateral adrenal hyperplasia (IAH) [2]. Compared to essential hypertension, PA is associated with a higher prevalence of cardiovascular and renal complications [3,4]. The correction of aldosterone excess reduces cardiovascular and overall mortality to that of essential hypertension patients [5]. The role of parathyroid hormone (PTH) and its influence on aldosterone secretion as well as the effect of aldosterone excess on the calcium phosphate homeostasis are so far not clearly understood. Recent studies support a bidirectional interaction between the two hormonal systems [6-8]. Increased levels of PTH have been demonstrated in PA patients, possibly triggered through aldosterone-mediated tubular calcium and magnesium losses [9-12]. In addition, several case reports of coincident PA and primary hyperparathyroidism have been reported [13-15]. The coexistence of increased PTH levels and aldosterone overproduction may increase the individual cardiovascular risk with ultimately adverse outcome [16].

Our aim was to perform a case finding of primary and secondary hyperparathyroidism in one of the largest PA dataset, the German Conn's Registry and to analyse the changes in calcium, phosphate, PTH and 25-hydroxyvitamin D following PA directed therapy.

\section{Patients and Methods}

\section{Study population}

The German Conn's registry - Else Kröner-Fresenius Hyperaldosteronismus registry was established in 2008 [5]. It documents diagnosis, therapy and outcome of patients with PA in Germany. A total of 503 patients from the centers in Munich $(n=313)$, Berlin $(n=$ 114), and Würzburg $(n=76)$ diagnosed between 1995 and March 2014 were included. The German Conn's registry has been approved by the local ethical committee. Written informed consent was obtained from all subjects.

The diagnosis of PA was based on the guidelines of the Endocrine Society as described before $[2,17]$. In short, the patients had arterial hypertension, an elevated aldosterone to renin ratio (ARR) and abnormal confirmatory test (saline infusion test, fludrocortisone suppression test, captopril test or oral salt loading test). The patients were studied without antihypertensive medication during diagnostic procedures whenever possible. Adjustment of medication prior to screening and confirmation was performed according to the guidelines, with beta-blockers, central alpha-2 agonists, angiotensin-converting enzyme inhibitors, angiotensin receptor blockers and diuretics withdrawn for at least 1 week, and mineralocorticoid receptor antagonists for at least 4 weeks. If blood pressure required antihypertensive medication, preferably the calcium channel blocker verapamil and the alpha-adrenoceptor antagonist doxazosin were used. Subtype differentiation was determined using adrenal vein sampling as described earlier [18]. We used a selectivity index of $\geq 2$ and a lateralization index of $\geq 4$ for the diagnosis of unilateral aldosterone excess. One year after initiation of PAbased therapy, patients were reevaluated.

\section{Association between PA and hyperparathyroidism}

To investigate the association between PA and hyperparathyroidism, a two-step approach was used.

\section{Cohort 1}

We used the data base of the German Conn's registry for case finding of primary hyperparathyroidism as referred to in the medical diagnosis list. In total, 503 patients with PA were included (296 studied retrospectively after initiation of specific PA therapy, 207 patients diagnosed prospectively). The patients of this cohort were not systematically screened for primary hyperparathyroidism, but serum calcium determinations were part of the routine laboratory in the majority of patients.

\section{Cohort 2}

We analysed 141 consecutive and prospective PA patients who underwent routine intact PTH (iPTH), serum calcium and serum phosphate measurements at the time of diagnosis of PA. The systematic screening was started in 2008. Hundred and twenty five of these 141 patients had a PA subtype differentiation (70 APA, 55 IAH). Of the 70 APA patients who underwent surgery 33 had a follow-up of 12 months after adrenalectomy. 27 of the 55 IAH patients had a follow-up investigation 12 months after initiation of mineralocorticoid receptor antagonist therapy. The other patients did not have a follow up at the time of the analysis or were lost to follow up.

Stored $24 \mathrm{~h}$ urine samples of 33 APA patients were analysed for calcium levels at time of diagnosis and one year after unilateral adrenalectomy. Subjects did not receive a special ion diet during urine collection. All samples were measured in one run.

\section{Definitions}

Secondary hyperparathyroidism was diagnosed if iPTH levels were $>65 \mathrm{pg} / \mathrm{mL}$ with albumin-corrected calcium in the lower normal range or below normal. Primary hyperparathyroidism was diagnosed if iPTH levels were $>65 \mathrm{pg} / \mathrm{mL}$ with albumin-corrected serum calcium $>2.6 \mathrm{mmol} / \mathrm{L}$. In these patients parathyroid ultrasound was performed in order to identify a parathyroid adenoma. Hypokalemia was defined as serum potassium $<3.5 \mathrm{mmol} / \mathrm{l}$.

Cardiovascular events were classified according to the International Classification of Diseases, $10^{\text {th }}$ revision: atrial fibrillation (148.), coronary heart disease (125.), acute coronary syndrome (defined as myocardial infarction (121.) or instable angina pectoris (I20.)) and cardiac insufficiency (I50.). Cerebrovascular events included stroke (164.), transient ischemic attack (G45.90) and cerebrovascular stenosis (I67.). Cumulative cardiovascular morbidity was defined as the sum of atrial fibrillation, coronary heart disease, cardiac insufficiency, stroke, transient ischemic attack and cerebrovascular stenosis. Only single independent events per patient were used and documented in the database.

\section{Analytical methods}

Before 2006, aldosterone was measured using either a commercial radioimmunoassay (RIA) (Maia Adaltis Italia S.p.a., Casalecchio di Reno, Italy and Coat-a-Count, Siemens, Los Angeles, CA, USA) or a chemiluminescence immunoassay (Nichols Advantage, Nichols Institute, San Clemente, CA, USA). Since 2006, all plasma aldoster- 
one measurements were performed with Coat-a-Count-RIA (Biermann DPC, Bad Nauheim, Germany). Since 2007 active renin concentration was measured by the Diasorin assay (Liaison, Saluggia, Italy) in Munich and with the Cisbio assay (Berlin, Germany) in Berlin and before that as renin activity with the Maia Adaltis Italia assay (Casalecchio di Reno, Italy). In our hands, the respective within- and between-assay coefficients of variation were below $9 \%$ and $12 \%$ for aldosterone and below $5.6 \%$ and $12.2 \%$ for renin.

IPTH was determined in serum by electro-chemiluminescence immunoassay (ECLIA) with the PTH STAT test (Cobas ${ }^{\circledR}$ Integra, Roche, Mannheim, Germany). Measurement of 25-hydroxyvitamin D was performed with the IDS iSYS kit (Immunodiagnostic Systems $\mathrm{GmbH}$, Frankfurt/Main, Germany). Total serum and urine calcium were measured using the CA test, serum phosphate and urine phosphate were measured by using Phosphate (Inorganic) vers.2, all Cobas $^{\circledR}$ Integra (Roche Diagnostics, Mannheim, Germany). All other biochemical variables were assayed in plasma or serum in our central laboratory using standard methods.

\section{Statistics and ethics}

If not stated otherwise, results are expressed as median and $25^{\text {th }}$ $75^{\text {th }}$ percentiles. Data between groups were compared using MannWhitney $\mathrm{U}$ test. Within group changes from baseline to follow-up were calculated by Wilcoxon signed-rank-test. $X 2$ test was used to compare frequency distributions. $\mathrm{P}<0.05$ was considered to be statistically significant. Statistical analysis was performed using standard statistical software (SPSS 23, IBM USA).

\section{Results}

\section{Prevalence of primary hyperparathyroidism in the German Conn's Registry (cohort 1)}

Six of 503 PA patients (1.2\%) of the Conn's registry had a documented diagnosis of primary hyperparathyroidism. Three of the 6 patients received the diagnosis of primary hyperparathyroidism after the diagnosis of PA was established (after 2, 2.5, and 7 years, respectively). One patient received the diagnosis of primary hyperparathyroidism at the time of the diagnosis of PA. In the remaining 2 patients the diagnosis of primary hyperparathyroidism was established 8 months and 1 year before the diagnosis of PA, respectively. Two of the 6 primary hyperparathyroidism/PA patients had an APA and underwent adrenalectomy, 1 patient had an IAH, and in the remaining patients no subtype differentiation was performed. All the patients underwent parathyroidectomy; histopathology revealed a single adenoma in all cases, and postoperative serum calcium and PTH levels returned to normal.

\section{Prevalence of primary and secondary hyperparathyroidism in prospectively diagnosed PA patients (cohort 2)}

The prevalence for primary hyperparathyroidism was $2.1 \%$ (3 of 141 patients) and $54.6 \%$ for secondary hyperparathyroidism (77 of 141 patients). We classified 138 prospectively studied patients into those having normal PTH levels ( $n=61$, no hyperparathyroidism) and patients having elevated PTH and low-normal or low serum calcium levels ( $n=77$, secondary hyperparathyroidism). Patients with secondary hyperparathyroidism had significantly higher aldosterone $(p=0.003)$ and lower potassium levels $(p=0.002)$ and took more antihypertensive medications $(p=0.025)$ compared to patients with normal iPTH levels (see - Table 1). Patients with secondary hyperparathyroidism suffered from lower 25-hydroxyvitamin D levels $(p=0.021)$. A total of 4 patients were on 25 -hydroxyvitamin $D$ supplementation. In multivariate analysis, aldosterone $(B=0.209, p=0.000$ ) and 25-hydroxyvitamin $D$ levels $(B=-0.257, p=0.000$ ) were significantly correlated with serum iPTH levels. When comparing the cumulative cardiovascular morbidity, there was a nonsignificant trend to a higher morbidity in patients with secondary hyperparathyroidism.

Hundred twenty five of 141 patients (89\%) underwent subtype determination of PA using adrenal vein sampling. As expected, APA patients $(n=70)$ had significantly higher aldosterone $(p=0.012)$ and lower potassium values $(p=0.000)$ compared to IAH $(n=55)$ patients. Further, APA patients had significantly higher iPTH levels compared to patients with IAH ( $p=0.007)$. In APA patients there were $1.4 \%$ with primary hyperparathyroidism and $68.6 \%$ with secondary hyperparathyroidism, in IAH patients there were $1.8 \%$ with primary hyperparathyroidism and $40.0 \%$ with secondary hyperparathyroidism $(p=0.006)$. Characteristics of the study population are presented in $>$ Table 2.

\section{Analysis one year after initiation of treatment of PA (cohort 2, $\mathrm{n}=60$ )}

We re-analysed 33 patients with APA and 27 patients with IAH one year after initiation of treatment. Adrenalectomy resulted in expected improvements of blood pressure and aldosterone levels and normalisation of potassium levels. In addition, there was a significant decrease of iPTH levels ( $p=0.001$, see $>$ Table 3 and $>$ Fig. 1 b) and a significant increase of serum calcium levels $(p=0.001$, see - Fig. 1a). Levels of 25-hydroxyvitamin D did not change significantly. In none of the patients substitution with cholecalciferol had been initiated in the meantime.

Urinary analysis of 33 APA patients at diagnosis and 1 year after adrenalectomy revealed a significant decrease of urinary calcium excretion $(p=0.003)$ (See $>$ Fig. 2).

Similar results were found in the $27 \mathrm{IAH}$ patients analysed 1 year after initiation of mineralocorticoid receptor antagonist treatment (see $>$ Table 4, $>$ Fig. 1c and d).

\section{Discussion}

The main findings of our manuscript are twofold: a) we determine the prevalence of primary (1-2\%) or secondary hyperparathyroidism ( $55 \%$ ) in patients with PA and show that hyperparathyroidism is more frequent in patients with more severe $P A$; b) we show that correction of PA by surgical or medical means alleviates secondary hyperparathyroidism.

The occurrence of PA and hyperparathyroidism is probably not only coincidental. Despite intensive research it remains unclear whether hyperparathyroidism triggers PA or whether high aldosterone levels are more relevant for the perturbation of calcium homeostasis. On the basis of gene expression and immunohistochemistry studies, Maniero et al. were the first to demonstrate that the 
- Table 1 Characteristics of PA patients with secondary hyperparathyroidism and normal PTH at time of diagnosis of PA. Data are median (25 th $-75^{\text {th }}$ percentile).

\begin{tabular}{|c|c|c|c|}
\hline & No hyperparathyroidism & Secondary hyperparathyroidism & $\mathbf{p}$ \\
\hline $\mathbf{n}$ & 61 & 77 & - \\
\hline Age $(y)$ & $47.0(42.0 ; 59.5)$ & $48.0(42.0 ; 55.5)$ & 0.777 \\
\hline Gender $(\mathrm{f} / \mathrm{m})$ & $22 / 39$ & $31 / 46$ & 0.615 \\
\hline BMI $\left(\mathrm{kg} / \mathrm{m}^{2}\right)$ & $26.8(24.9 ; 30.5)$ & $28.3(25.9 ; 30.9)$ & 0.123 \\
\hline Systolic blood pressure $(\mathrm{mmHg})$ & $152(139 ; 166)$ & $153(140 ; 170)$ & 0.845 \\
\hline Diastolic blood pressure $(\mathrm{mmHg})$ & $94(85 ; 106)$ & $94(87 ; 105)$ & 0.796 \\
\hline Duration hypertension $(\mathrm{y})$ & $8.0(2.0 ; 14.8)$ & $8.0(2.0 ; 13.0)$ & 0.610 \\
\hline Hypokalemic PA (\%) & 67.2 & 81.8 & 0.048 \\
\hline $\operatorname{GFR}\left(\mathrm{ml} / \mathrm{min} / 1,73 \mathrm{~m}^{2}\right)$ & $94.2(86.6 ; 104.8)$ & $88.8(74.3 ; 100.2)$ & 0.054 \\
\hline Aldosterone (ng/l) & 151 (101.5; 187.5) & $200.0(139.0 ; 349.0)$ & 0.003 \\
\hline Renin (mIU/l) & $3.8(2.0 ; 5.9)$ & $3.9(2.1 ; 7.4)$ & 0.609 \\
\hline Potassium (mmol/l) & $3.7(3.3 ; 3.8)$ & $3.3(3.0 ; 3.6)$ & 0.002 \\
\hline Total serum Calcium (mmol/l) & $2.39(2.34 ; 2.46)$ & $2.33(2.26 ; 2.40)$ & 0.001 \\
\hline $\mathrm{PO} 4$ (mg/dl) & $3.0(2.5 ; 3.4)$ & $2.8(2.2 ; 3.2)$ & 0.133 \\
\hline iPTH (pg/ml) & $49.2(45.6 ; 58.7)$ & $82.5(72.1 ; 105.0)$ & 0.000 \\
\hline 25-hydroxyvitamin D (ng/ml) & $22.7(16.1 ; 34.6)$ & $18.7(12.2 ; 26.9)$ & 0.021 \\
\hline Cumulative cardiovascular morbidity (\%) & 21.3 & 31.2 & 0.166 \\
\hline Atrial fibrillation (\%) & 4.9 & 7.8 & 0.497 \\
\hline Coronary heart disease (\%) & 4.9 & 5.2 & 0.941 \\
\hline Acute coronary syndrome (\%) & 0 & 3.9 & 0.119 \\
\hline Cardiac insufficiency (\%) & 6.6 & 11.7 & 0.305 \\
\hline Stroke $(\%)$ & 0 & 3.9 & 0.119 \\
\hline Cerebrovasc. stenosis (\%) & 4.9 & 2.6 & 0.469 \\
\hline
\end{tabular}

mineralocorticoid receptor is present in the parathyroid gland whereas the PTH receptor type 1 is present in the adrenal gland in a patient with concomitant PA and primary hyperparathyroidism [15]. Brown et al. could demonstrate a 2- to 4-fold increase of mineralocorticoid and angiotensin II type 1 receptors in adenomatous tissue of the parathyroid gland [19]. A recent study of Lenzini et al. in primary culture of human parathyroid cells showed that both aldosterone and angiotensin II increased PTH secretion, by acting through MR and angiotensin II type 1 receptors, respectively [8].

It is a well-established clinical observation that the majority of patients with primary hyperparathyroidism suffer from hypertension $[20,21]$. A prospective analysis showed a positive correlation between preoperative PTH levels and aldosterone plasma concentration [22]. Different studies could demonstrate that blood pressure is reduced after parathyroidectomy with a decline of reninangiotensin-aldosterone-system activation [22, 23]. A possible explanation is that PTH directly increases aldosterone production from the adrenal glands or stimulates aldosterone through activation of the renin-angiotensin-aldosterone-system [24, 25].

The prevalence of primary hyperparathyroidism is 233 per 100000 in women and 85 per 100000 in men [26]. In a large longitudinal prospective study of older women, hypertension was associated with a $45 \%$ higher risk of developing primary hyperparathyroidism than that of participants without a diagnosis of hypertension [27]. Over the last 30 years a number of case reports noted the coincidence of PA and primary hyperparathyroidism $[13,15]$. Here, we describe a series of 6 patients with coincidental PA and primary hyperparathyroidism. The diagnosis of primary hyperparathyroidism occurred before, at the same time and after the diagnosis of PA. A retrospective analysis of $306 \mathrm{PA}$ patients revealed a slightly higher primary hyperparathyroidism prevalence of $2.6 \%$ [14]. Up to now both diseases are usually treated independently. An improved understanding of the interdependence of PA and primary hyperparathyroidism would have the potential to influence these mechanisms earlier and with more targeted approaches.

Significant associations between plasma aldosterone and PTH were found in several population based studies [28-30]. We reported a significant association of high ARR with high PTH concentrations in the general population of northeast Germany [31]. Another study described significant associations between aldosterone, ARR and PTH levels independent of vitamin D status, phosphate levels, calcium, antihypertensive agents, coronary heart disease, cardiac insufficiency and kidney function [32]. In the present investigation, we found a significant correlation of aldosterone and 25-hydroxyvitamin D levels with serum PTH levels. A study found that serum potassium and calcium levels were the main factors influencing the plasma PTH levels in PA patients [33].

Several studies demonstrated that PTH levels are higher and serum calcium levels are lower in patients with PA in comparison to patients with essential hypertension $[9-12,33,34]$. These results were recently emphasised in a meta-analysis involving 748 subjects from 6 case-control-studies [35]. In our current evaluation, $54.6 \%$ of newly diagnosed PA patients had elevated iPTH levels resembling secondary hyperparathyroidism. We observed that 
- Table 2 Baseline characteristics of 125 of 141 patients who had subtype determination by adrenal vein sampling. Data are given as median ( $25^{\text {th }}-75^{\text {th }}$ percentile).

\begin{tabular}{|c|c|c|c|c|}
\hline & Total PA & APA & IAH & $\mathbf{p}$ \\
\hline $\mathbf{n}$ & 125 & 70 & 55 & - \\
\hline Age $(y)$ & $47(42 ; 56)$ & $49(43 ; 59)$ & $45(41 ; 53)$ & 0.079 \\
\hline Gender $(\mathrm{f} / \mathrm{m})$ & $46 / 79$ & $26 / 44$ & $20 / 35$ & 0.929 \\
\hline BMI $\left(\mathrm{kg} / \mathrm{m}^{2}\right)$ & $27.9(25.5 ; 30.9)$ & $28.0(25.8 ; 30.9)$ & $27.7(25.2 ; 31.0)$ & 0.629 \\
\hline Systolic blood pressure (mmHg) & $153(140 ; 166)$ & $153(140 ; 162)$ & $152(135 ; 169)$ & 0.877 \\
\hline Diastolic blood pressure $(\mathrm{mmHg})$ & $95(87 ; 105)$ & $94(87 ; 103)$ & $96(87 ; 110)$ & 0.366 \\
\hline Duration hypertension (y) & $8(2 ; 14)$ & $8(3 ; 15)$ & $9(1 ; 13)$ & 0.784 \\
\hline Hypokalemic PA (\%) & 76.8 & 90.0 & 60.0 & 0.000 \\
\hline GFR $\left(\mathrm{ml} / \mathrm{min} / 1,73 \mathrm{~m}^{2}\right)$ & $93.0(78.7 ; 102.0)$ & $87.6(72.9 ; 101.7)$ & $93.80(88.6 ; 103.2)$ & 0.087 \\
\hline Aldosterone (ng/l) & $173.0(123.5 ; 277.0)$ & $195.5(141.8 ; 364.0)$ & $160.0(107.0 ; 221.0)$ & 0.012 \\
\hline $\operatorname{Renin}(\mathrm{mlU} / \mathrm{l})$ & $3.5(2.0 ; 5.8)$ & $3.9(2.0 ; 6.2)$ & $3.9(2.0 ; 7.5)$ & 0.451 \\
\hline Potassium (mmol/l) & $3.4(3.1 ; 3.8)$ & $3.3(3.0 ; 3.6)$ & $3.7(3.3 ; 3.8)$ & 0.000 \\
\hline Total serum Calcium (mmol/l) & $2.4(2.3 ; 2.4)$ & $2.3(2.3 ; 2.4)$ & $2.39(2.31 ; 2.43)$ & 0.011 \\
\hline $\mathrm{PO} 4(\mathrm{mg} / \mathrm{dl})$ & $2.9(2.2 ; 3.3)$ & $2.9(2.2 ; 3.2)$ & $3.00(2.40 ; 3.30)$ & 0.395 \\
\hline iPTH $(\mathrm{pg} / \mathrm{ml})$ & $67.7(50.9 ; 88.1)$ & $72.1(62.2 ; 90.8)$ & $61.8(46.4 ; 85.1$ & 0.007 \\
\hline 25-hydroxyvitamin D (ng/ml) & $20.9(13.6 ; 29.0)$ & $19.6(13.9 ; 25.8)$ & $24.4(12.7 ; 32.0)$ & 0.359 \\
\hline Primary hyperparathyroidism (\%) & 1.6 & 1.4 & 1.8 & 0.006 \\
\hline Secondary hyperparathyroidism (\%) & 56.0 & 68.6 & 40.0 & \\
\hline Cumulative cardiovascular morbidity (\%) & 24.8 & 30.0 & 10.0 & 0.095 \\
\hline Atrial fibrillation (\%) & 6.4 & 10.0 & 1.8 & 0.064 \\
\hline Coronary heart disease (\%) & 4.8 & 2.9 & 7.3 & 0.252 \\
\hline Acute coronary syndrome (\%) & 1.6 & 1.4 & 1.8 & 0.863 \\
\hline Cardiac insufficiency (\%) & 8.0 & 8.6 & 7.3 & 0.790 \\
\hline Stroke (\%) & 2.4 & 4.3 & 0 & 0.120 \\
\hline Cerebrovasc. stenosis (\%) & 3.2 & 4.3 & 1.8 & 0.437 \\
\hline Albumin in spot urine $(\mathrm{mg} / \mathrm{dl})$ & $1.4(0.7 ; 4.0)$ & $1.9(1.2 ; 5.6)$ & $1.2(0.5 ; 1.8)$ & 0.001 \\
\hline
\end{tabular}

- Table 3 Characteristics of 33 APA patients before and 1 year after adrenalectomy. Data are median $\left(25^{\text {th }}-75^{\text {th }}\right.$ percentile).

\begin{tabular}{|c|c|c|c|}
\hline & APA before adrenalectomy & APA after adrenalectomy & $\mathbf{p}$ \\
\hline $\mathbf{n}$ & \multicolumn{2}{|c|}{33} & - \\
\hline Gender $(\mathrm{f} / \mathrm{m})$ & \multicolumn{2}{|c|}{$14 / 19$} & - \\
\hline BMI $\left(\mathrm{kg} / \mathrm{m}^{2}\right)$ & $28.3(26.8 ; 31.5)$ & $28.4(26.6 ; 31.4)$ & 0.551 \\
\hline Systolic blood pressure $(\mathrm{mmHg})$ & 149 (138: 160) & $133(120 ; 141)$ & 0.000 \\
\hline Diastolic blood pressure $(\mathrm{mmHg})$ & $91(85 ; 103)$ & $88(80 ; 93)$ & 0.021 \\
\hline GFR $\left(\mathrm{ml} / \mathrm{min} / 1,73 \mathrm{~m}^{2}\right)$ & $86.0(75.2 ; 100.1)$ & $75.0(63.3 ; 90.2)$ & 0.000 \\
\hline Aldosterone (ng/l) & $188.0(136.0 ; 394.5)$ & $61.0(35.0 ; 112.5)$ & 0.000 \\
\hline $\operatorname{Renin}(\mathrm{mlU} / \mathrm{l})$ & $3.6(1.8 ; 4.5)$ & $14.2(6.0 ; 30.6)$ & 0.000 \\
\hline Potassium (mmol/l) & $3.2(3.0 ; 3.6)$ & $4.1(3.8 ; 4.4)$ & 0.000 \\
\hline Total serum Calcium (mmol/l) & $2.34(2.23 ; 2.36)$ & $2.39(2.32 ; 2.48)$ & 0.001 \\
\hline $\mathrm{PO} 4$ (mg/dl) & $2.9(2.1 ; 3.1)$ & $3.0(2.4 ; 3.5)$ & 0.125 \\
\hline iPTH (pg/ml) & $71.2(58.9 ; 90.5)$ & $48.7(38.4 ; 57.7)$ & 0.001 \\
\hline 25-hydroxyvitamin D (ng/ml) & $19.9(16.8 ; 25.4)$ & $19.6(15.8 ; 31.7)$ & 0.280 \\
\hline Albumin in spot urine $(\mathrm{mg} / \mathrm{dl})$ & $2.1(1.2 ; 9.4)$ & $1.0(0.5 ; 1.3)$ & 0.000 \\
\hline
\end{tabular}

iPTH levels were significantly higher in APA patients in comparison to patients with IAH. Lately, Rossi et al. hypothesised hyperparathyroidism as being a novel feature of PA and postulated that measuring PTH levels might help to distinguish between APA and IAH as APA patients showed higher PTH levels [12]. However, no differ- ence between the PA subtypes was found in other recent studies $[33,36]$.

A number of studies could demonstrate that after treatment of PA, serum calcium levels increase and PTH levels decline [9-11,33]. A randomized, placebo-controlled interventional study in subjects 
a

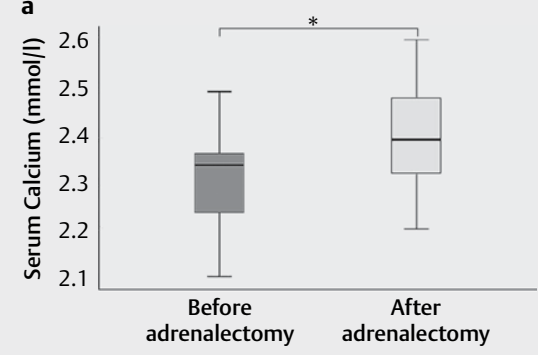

b

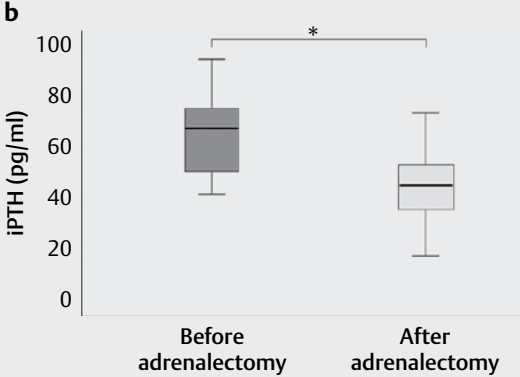

c

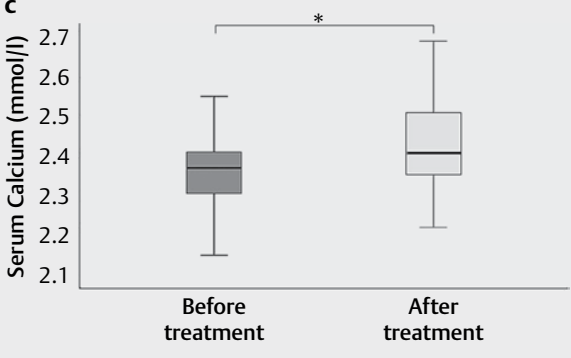

d

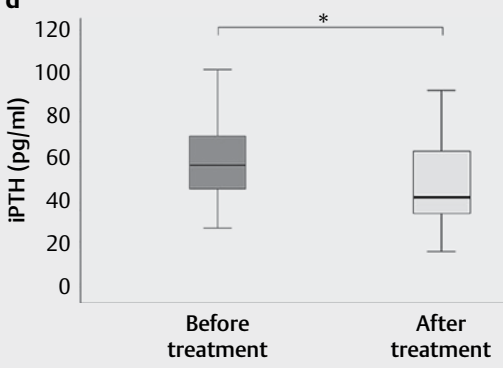

- Fig. 1 a Total serum calcium levels (mmol/l) of 33 APA patients before and 1 year after adrenalectomy b iPTH levels (pg/ml) of 33 APA patients before and 1 year after adrenalectomy c Total serum calcium levels ( $\mathrm{mmol} / \mathrm{I})$ of $27 \mathrm{IAH}$ patients before and after treatment with mineralocorticoid receptor antagonist $\mathbf{d}$ iPTH levels (pg/ml) of $27 \mathrm{IAH}$ patients before and after treatment with mineralocorticoid receptor antagonist.
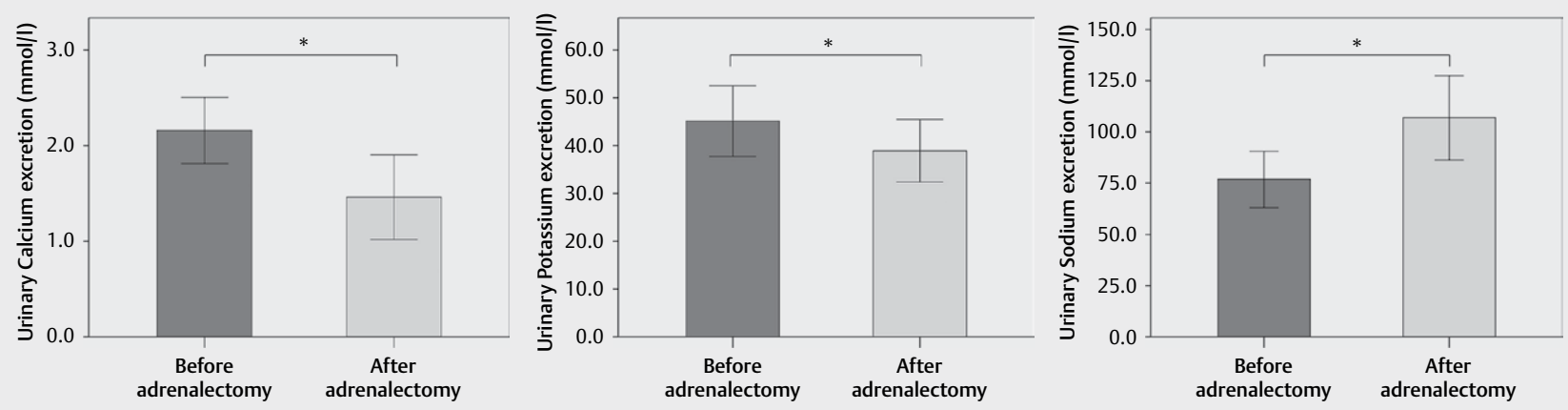

- Fig. 2 Urinary excretion of sodium, potassium and calcium in 33 patients with APA initially and one year after adrenalectomy. Subjects did not receive a special ion diet during urine collection.

with normal aldosterone levels demonstrated that six weeks of treatment with the mineralocorticoid receptor antagonist spironolactone resulted in a relative decrease in PTH compared to placebo [19]. Recently, the study of Lenzini et al. showed that the inhibition of angiotensin II with captopril lowered PTH levels both in essential hypertension and in APA patients after adrenalectomy [8]. Interestingly, captopril had no effect on the elevated PTH levels in PA patients, suggesting that the parathyroid gland loses its ability to respond to acute angiotensin II inhibition when hyperaldosteronism coexists with hyperparathyroidism. In the present series, we could demonstrate a significant decrease of PTH levels with a significant increase of serum calcium levels after adrenalectomy in APA patients as well as after initiation of treatment with mineralocorticoid receptor antagonists in patients with IAH. Levels of $25-\mathrm{OH}$ vitamin $\mathrm{D}$ remained stable, which indicates that vitamin $\mathrm{D}$ deficien- cy is an unlikely mechanism to explain the secondary hyperparathyroidism seen in PA. We show that calcium urine excretion was disproportionately increased in newly diagnosed PA patients. After adrenalectomy, urine calcium levels decreased significantly, as shown before [10,37]. These observations support the theory that PA patients suffer from renal (and potentially intestinal) calcium wasting with hypocalcemia and compensatory increase of PTH with development of secondary hyperparathyroidism. Also, expanded extravascular fluid volume with decreased proximal reabsorption of sodium and calcium and increase of the distal delivery with a distal reabsorption of sodium but not of calcium might explain secondary hyperparathyroidism [38]. Prolonged secondary hyperparathyroidism might eventually lead to tertiary hyperaldosteronism with one parathyroid adenoma in some patients. 
- Table 4 Characteristics of $27 \mathrm{IAH}$ patients before and after treatment with mineralocorticoid receptor antagonist. Data are median $\left(25^{\text {th }}-75^{\text {th }}\right.$ percentile).

\begin{tabular}{|c|c|c|c|}
\hline & IAH before therapy & IAH after therapy & $\mathbf{p}$ \\
\hline n & \multicolumn{2}{|c|}{27} & \\
\hline Gender (f/m) & \multicolumn{2}{|c|}{$8 / 19$} & \\
\hline BMI $\left(\mathrm{kg} / \mathrm{m}^{2}\right)$ & $28.7(25.3 ; 31.0)$ & $27.8(25.1 ; 30.4)$ & 0.595 \\
\hline Systolic blood pressure $(\mathrm{mmHg})$ & $151(135 ; 166)$ & $135(122 ; 149)$ & 0.006 \\
\hline Diastolic blood pressure $(\mathrm{mmHg})$ & $94(110 ; 87)$ & $85(80 ; 92)$ & 0.020 \\
\hline GFR $\left(\mathrm{ml} / \mathrm{min} / 1,73 \mathrm{~m}^{2}\right)$ & $95.6(93.0 ; 104.6)$ & $89.3(78.3 ; 106.5)$ & 0.029 \\
\hline Aldosterone (ng/l) & $167.0(123.0 ; 217.0)$ & $216.0(143.0 ; 388.6)$ & 0.023 \\
\hline Renin (mIU/l) & $4.1(2.0 ; 7.9)$ & $15.9(5.4 ; 29.4)$ & 0.001 \\
\hline Potassium (mmol/l) & $3.7(3.2 ; 3.8)$ & $4.0(3.0 ; 4.3)$ & 0.000 \\
\hline Spironolactone dose (mg/day) & - & $50(25 ; 50)$ & - \\
\hline Total serum Calcium (mmol/l) & $2.37(2.30 ; 2.42)$ & $2.41(2.34 ; 2.52)$ & 0.025 \\
\hline $\mathrm{PO} 4(\mathrm{mg} / \mathrm{dl})$ & $3.1(2.6 ; 3.4)$ & $2.9(2.4 ; 3.4)$ & 0.174 \\
\hline iPTH (pg/ml) & $58.4(47.0 ; 72.1)$ & $43.0(35.4 ; 64.7)$ & 0.012 \\
\hline 25-hydroxyvitamin D (ng/ml) & $25.5(13.2 ; 31.1)$ & $26.1(19.3 ; 35.4)$ & 0.123 \\
\hline Albumin in spot urine (mg/dl) & $1.1(0.5 ; 2.3)$ & $0.4(0.3 ; 1.0)$ & 0.01 \\
\hline
\end{tabular}

PA and hyperparathyroidism are associated with a higher cardiovascular morbidity [3-6, 39, 40]. In fact, elevated PTH levels have been shown to represent an independent risk factor for mortality and cardiovascular events $[28,40]$. In patients with primary hyperparathyroidism, cardiovascular morbidity is reduced after parathyroidectomy [39, 41, 42]. In a recent study, systolic blood pressure variability was increased in patients with primary hyperparathyroidism and was reduced by parathyroidectomy [43]. Short-term blood pressure variability parameters were not available in this study. As reviewed by Tomaschitz et al., the relationship between aldosterone and PTH might explain the higher cardiovascular risk in hyperparathyroidism [6, 9]. Similarly, an important role in the pathogenesis of cardiac remodelling in PA has been lately attributed to PTH [44]. In an investigation of patients referred to coronary angiography, multivariate analysis revealed that both plasma aldosterone and PTH were independently associated with cardiovascular mortality, with evidence for a synergistic interaction [32]. In our analysis, we found a nonsignificant trend of a higher cardiovascular morbidity in patients with secondary hyperparathyroidism compared to patients with normal PTH levels.

The relationship between renin-angiotensin-aldosterone-system and the calcium phosphate homeostasis might offer therapeutic targets in affected patients. The study Effects of Eplerenone in Patients with primary hyperparathyroidism (EPATH) investigated the effect of the mineralocorticoid receptor antagonist eplerenone on PTH levels as well as cardiovascular outcome in patients with pPTH [45]. Treatment with eplerenone had no effect on circulating iPTH levels but was followed by a significant decrease of ambulatory blood pressure. The ongoing interventional renin-angiotensin-aldosterone-system and PTH Control (RAAS-PARC) study evaluates the effect of angiotensin converting enzyme inhibition on PTH levels in primary hyperparathyroidism (NCT01691781). More studies are needed to shed new light onto the clinical impact of the observed relationship between PA and hyperparathyroidism.

\section{Limitations of our study}

This is a retrospective investigation. Especially in cohort 1 there is a likelihood of underreporting of primary hyperparathyroidism. Clinical data as reported here describe associations but not causality. The sampling of paired plasma and urine probes of cohort 2 was done in clinical routine, and not during a standardized ion diet, which may have affected the results due to dietary variations. UAE was measured on spot urine.

\section{Acknowledgements}

The study was only feasible due to the support of our PA team and the Endocrine laboratory team in Munich.

\section{Funding}

This work was supported by the Else Kröner-Fresenius Stiftung in support of the German Conns Registry-Else-Kröner Hyperaldosteronism Registry (2013_A182 and 2015_A171 to MR), the European Research Council (ERC) under the European Union's Horizon 2020 research and innovation programme (grant agreement No [6949 13] to MR), by the Deutsche Forschungsgemeinschaft (DFG) (within the CRC/Transregio 205/1 "The Adrenal: Central Relay in Health and Disease" to FB and MR).

\section{Conflict of Interest}

The authors declare that they have no conflict of interest. 


\section{References}

[1] Rossi GP, Bernini G, Caliumi C et al. A prospective study of the prevalence of primary aldosteronism in 1125 hypertensive patients. J Am Coll Cardiol 2006; 48: 2293-2300. DOI: S0735-1097(06)02332-1 [pii]. doi:10.1016/j.jacc.2006.07.059

[2] Funder JW, Carey RM, Mantero F et al. The management of primary aldosteronism: Case detection, diagnosis, and treatment: An endocrine society clinical practice guideline. J Clin Endocrinol Metab 2016; 101: 1889-1916. doi:10.1210/jc.2015-4061

[3] Catena C, Colussi G, Nadalini E et al. Cardiovascular outcomes in patients with primary aldosteronism after treatment. Arch Intern Med 2008; 168: 80-85. doi:10.1001/archinternmed.2007.33

[4] Milliez P, Girerd X, Plouin PF et al. Evidence for an increased rate of cardiovascular events in patients with primary aldosteronism. J Am Coll Cardiol 2005; 45: 1243-1248. doi:10.1016/j.jacc.2005.01.015

[5] Reincke M, Fischer E, Gerum S et al. Observational study mortality in treated primary aldosteronism: The German Conn's Registry. Hypertension 2012, HYPERTENSIONAHA.112.197111 [pii]. doi:10.1161/HYPERTENSIONAHA.112.197111

[6] Tomaschitz A, Ritz E, Pieske B et al. Aldosterone and parathyroid hormone: A precarious couple for cardiovascular disease. Cardiovasc Res 2012; 94: 10-19. DOI: cvs092 [pii]. doi:10.1093/cvr/cvs092

[7] Rossi GP. Hyperparathyroidism, arterial hypertension and aortic stiffness: A possible bidirectional link between the adrenal cortex and the parathyroid glands that causes vascular damage? Hypertens Res 2011; 34: 286-288. doi:10.1038/hr.2010.251

[8] Lenzini L, Prisco S, Vanderriele PE et al. PTH Modulation by Aldosterone and Angiotensin II is blunted in hyperaldosteronism and rescued by adrenalectomy. J Clin Endocrinol Metab 2019, doi:10.1210/ jc.2019-00143

[9] Pilz S, Kienreich K, Drechsler C et al. Hyperparathyroidism in patients with primary aldosteronism: Cross-sectional and interventional data from the GECOH study. J Clin Endocrinol Metab 2012; 97: E75-E79 DOI: jc.2011-2183 [pii]. doi:10.1210/jc.2011-2183

[10] Maniero C, Fassina A, Seccia TM et al. Mild hyperparathyroidism: A novel surgically correctable feature of primary aldosteronism. J Hypertens 2012; 30: 390-395. doi:10.1097/HJH.0b013e32834f0451

[11] Rossi E, Sani C, Perazzoli F et al. Alterations of calcium metabolism and of parathyroid function in primary aldosteronism, and their reversal by spironolactone or by surgical removal of aldosteroneproducing adenomas. Am J Hypertens 1995; 8: 884-893. DOI: 0895-7061(95)00182-O [pii] doi:10.1016/0895-7061(95)00182-O

[12] Rossi GP, Ragazzo F, Seccia TM et al. Hyperparathyroidism can be useful in the identification of primary aldosteronism due to aldosterone-producing adenoma. Hypertension 2012; 60: 431-436. DOI: HYPERTENSIONAHA.112.195891 [pii]. doi:10.1161/HYPERTENSIONAHA.112.195891

[13] Petramala L, Savoriti C, Zinnamosca L et al. Primary aldosteronism with concurrent primary hyperparathyroidism in a patient with arrhythmic disorders. Intern Med 2013; 52: 2071-2075

[14] Concistre A, Petramala L, Zinnamosca L et al. Primary aldosteronism with concurrent primary hyperparathyroidism: Clinical case load in a single centre. European Review for Medical and Pharmacological Sciences 2015; 19: 971-976

[15] Maniero C, Fassina A, Guzzardo V et al. Primary hyperparathyroidism with concurrent primary aldosteronism. Hypertension 2011; 58: 341-346. DOI: HYPERTENSIONAHA.111.173948 [pii]. doi:10.1161/ HYPERTENSIONAHA.111.173948

[16] Funder JW. ACE inhibitors and mineralocorticoid receptor blockade in patients with congestive heart failure. Curr Diab Rep 2005; 5: 36-40

[17] Fischer E, Adolf C, Pallauf A et al. Aldosterone excess impairs first phase insulin secretion in primary aldosteronism. J Clin Endocrinol Metab 2013; 98: 2513-2520. doi:10.1210/jc.2012-3934
[18] Vonend O, Ockenfels N, Gao X et al. Adrenal venous sampling: evaluation of the German Conn's registry. Hypertension 2011; 57 : 990-995. doi:10.1161/HYPERTENSIONAHA.110.168484

[19] Brown JM, Williams JS, Luther JM et al. Human interventions to characterize novel relationships between the renin-angiotensin-aldosterone system and parathyroid hormone. Hypertension 2014; 63: 273-280. doi:10.1161/HYPERTENSIONAHA.113.01910

[20] Hedback GM, Oden AS. Cardiovascular disease, hypertension and renal function in primary hyperparathyroidism. J Intern Med 2002; 251: 476-483. DOI: 984 [pii]

[21] Feldstein CA, Akopian M, Pietrobelli D et al. Long-term effects of parathyroidectomy on hypertension prevalence and circadian blood pressure profile in primary hyperparathyroidism. Clinical and Experimental Hypertension 2010; 32: 154-158. doi:10.3109/10641960903254471

[22] Brunaud L, Germain A, Zarnegar R et al. Serum aldosterone is correlated positively to parathyroid hormone (PTH) levels in patients with primary hyperparathyroidism. Surgery 2009; 146: 1035-1041. DOI: S0039-6060(09)00693-X [pii]. doi:10.1016/j.surg.2009.09.041

[23] Bernini G, Moretti A, Lonzi S et al. Renin-angiotensin-aldosterone system in primary hyperparathyroidism before and after surgery. Metabolism 1999; 48: 298-300

[24] Mazzocchi G, Aragona F, Malendowicz LK et al. PTH and PTH-related peptide enhance steroid secretion from human adrenocortical cells. Am J Physiol Endocrinol Metab 2001; 280: E209-E213

[25] Isales CM, Barrett PQ, Brines M et al. Parathyroid hormone modulates angiotensin II-induced aldosterone secretion from the adrenal glomerulosa cell. Endocrinology 1991; 129: 489-495

[26] Yeh MW, Ituarte PH, Zhou HC et al. Incidence and prevalence of primary hyperparathyroidism in a racially mixed population. I Clin Endocrinol Metab 2013; 98: 1122-1129. doi:10.1210/jc.2012-4022

[27] Vaidya A, Curhan GC, Paik JM et al. Hypertension, Antihypertensive Medications, and Risk of Incident Primary Hyperparathyroidism. J Clin Endocrinol Metab 2015; 100: 2396-2404. doi:10.1210/jc.2015-1619

[28] Pilz S, Tomaschitz A, Drechsler C et al. Parathyroid hormone level is associated with mortality and cardiovascular events in patients undergoing coronary angiography. Eur Heart J 2010; 31: 1591-1598 DOI: ehq109 [pii]. doi:10.1093/eurhearti/ehq109

[29] Tomaschitz A, Pilz S, Ritz E et al. Independent association between 1,25-dihydroxyvitamin $D, 25$-hydroxyvitamin $D$ and the renin-angiotensin system: The Ludwigshafen Risk and Cardiovascular Health (LURIC) study. Clin Chim Acta 2010; 411: 1354-1360. DOI: S00098981(10)00370-0 [pii]. doi:10.1016/j.cca.2010.05.037

[30] Brown J, de Boer IH, Robinson-Cohen C et al. Aldosterone, parathyroid hormone, and the use of renin-angiotensin-aldosterone system inhibitors: The multi-ethnic study of atherosclerosis. J Clin Endocrinol Metab 2015; 100: 490-499. doi:10.1210/jc.2014-3949

[31] Fischer E, Hannemann A, Rettig R et al. A high aldosterone to renin ratio is associated with high serum parathyroid hormone concentrations in the general population. J Clin Endocrinol Metab 2014; 99 : 965-971. doi:10.1210/jc.2013-3214

[32] Tomaschitz A, Pilz S, Rus-Machan J et al. Interrelated aldosterone and parathyroid hormone mutually modify cardiovascular mortality risk. International Journal of Cardiology 2015; 184: 710-716. doi:10.1016/j.ijcard.2015.03.062

[33] Jiang $Y$, Zhang $C$, Ye L et al. Factors affecting parathyroid hormone levels in different types of primary aldosteronism. Clin Endocrinol (Oxf) 2015, doi:10.1111/cen.12981

[34] Ceccoli L, Ronconi V, Giovannini L et al. Bone health and aldosterone excess. Osteoporosis international : A journal established as result of cooperation between the European Foundation for Osteoporosis and the National Osteoporosis Foundation of the USA. 2013; 24 2801-2807. doi:10.1007/s00198-013-2399-1 
[35] Zhang Y, Feng B. The association of serum parathyriod hormone and calcium levels with primary aldosteronism: A meta-analysis. Minerva Endocrinologica 2016

[36] Riester A, Fischer E, Degenhart C et al. Age below 40 or a recently proposed clinical prediction score cannot bypass adrenal venous sampling in primary aldosteronism. J Clin Endocrinol Metab 2014; 99 : E1035-E1039. doi:10.1210/jc.2013-3789

[37] Salcuni AS, Palmieri S, Carnevale V et al. Bone involvement in aldosteronism. J Bone Miner Res 2012, doi:10.1002/jbmr.1660

[38] Kamalov G, Bhattacharya SK, Weber KT. Congestive heart failure: Where homeostasis begets dyshomeostasis. Journal of Cardiovascular Pharmacology 2010; 56: 320-328. doi:10.1097| FJC.0b013e3181ed064f

[39] Rubin MR, Maurer MS, McMahon D] et al. Arterial stiffness in mild primary hyperparathyroidism. J Clin Endocrinol Metab 2005; 90: 3326-3330. DOI: jc.2004-1400 [pii]. doi:10.1210/jc.2004-1400

[40] Vestergaard P, Mollerup CL, Frokjaer VG et al. Cardiovascular events before and after surgery for primary hyperparathyroidism. World ] Surg 2003; 27: 216-222. doi:10.1007/s00268-002-6541-z
[41] Piovesan A, Molineri N, Casasso F et al. Left ventricular hypertrophy in primary hyperparathyroidism. Effects of successful parathyroidectomy. Clin Endocrinol (Oxf) 1999; 50: 321-328

[42] Rosa J, Raska I Jr., Wichterle D et al. Pulse wave velocity in primary hyperparathyroidism and effect of surgical therapy. Hypertens Res 2011; 34: 296-300. doi:10.1038/hr.2010.232

[43] Concistre A, Grillo A, La Torre G et al. Ambulatory blood pressure monitoring-derived short-term blood pressure variability in primary hyperparathyroidism. Endocrine 2018; 60: 129-137. doi:10.1007| s12020-017-1362-x

[44] Rutledge MR, Farah V, Adeboye AA et al. Parathyroid hormone, a crucial mediator of pathologic cardiac remodeling in aldosteronism. Cardiovascular drugs and therapy / sponsored by the International Society of Cardiovascular Pharmacotherapy 2013; 27: 161-170. doi:10.1007/s10557-012-6378-0

[45] Tomaschitz A, Verheyen N, Meinitzer A et al. Effect of eplerenone on parathyroid hormone levels in patients with primary hyperparathyroidism: Results from the EPATH randomized, placebo-controlled trial. J Hypertens 2016; 34: 1347-1356. 10.1097/HJH.0000000000000927 